Ahmad, R. and N. Scott (2016). "Why Minimum Wage Order implementation is a challenge to hotel managers in Langkawi." International Journal of Culture, Tourism, and Hospitality Research 10(2): 191-204.

\title{
Why Minimum Wage Order implementation is a challenge to hotel managers in Langkawi
}

Purpose - This paper explores the HR challenges faced by hotel managers in Langkawi due to the implementation of the Minimum Wage Order (MWO).

Design/ methodology/ approach - This study collected qualitative data from twenty managers from nineteen hotels of various sizes and level of service including budget and boutique resorts on Langkawi Island, Malaysia. Semi structured interview is used to ask the question "What are the challenges faced by hotel managers due to the implementation of the MWO?”

Findings - The challenges faced by the managers are: low employee productivity levels, many employees with a salary below the minimum wage rate, difficulty paying staff due to low revenue and issues related to the service charge.

Research limitations/ implications - This study provides an initial qualitative exploration of an important current legal development impacting hotel managers in Malaysia. It provides some initial findings from Langkawi but the findings may not represent the attitudes of hotel managers in other parts of Malaysia.

Practical implications - This study contributes to HR management literature by providing insight to challenges faced by four to five star hotel managers in a developing country. To the managers, the MWO guideline is a serious challenge as some of their employees are not productive enough to be paid at the minimum wage rate. To address increasing labour cost some have turned to the employment of foreign workers while others have increased their casual employee numbers. These insights may serve to guide policy makers and hotel managers in other developing countries that are planning to introduce a MWO.

Social implications - For the MWO to be effective, it is crucial for the government to develop effective guidelines for its implementation, and for employees amongst the Langkawi community to increase their level of productivity.

Originality/ value - The Malaysian MWO policy was introduced in 2012. The policy affects employees' remuneration and provides a challenge in implementation for the Malaysian hotel industry especially in 
Langkawi. While many studies on MWO implementation focus on unemployment this study provides the managers' perspective on the challenges faced due to the implementation of this policy and identifies reasons why the unemployment rate for local workers may increase after an MWO.

Keywords: Developing country, minimum wage, human resource management, hotel, Malaysia

\section{Article Classification: Research paper}

\section{Introduction}

The hotel industry is susceptible to external environmental impacts such as changes in government rules and regulations, economic downturns, and increases in labour costs (Nankervis, 2000). In May 2012, the government of Malaysia announced the implementation of a national minimum wage (MWO) policy for the private sector. This was set at Ringgit Malaysia (RM) 800 (British Pound 136) per month for Sabah, Sarawak and the Federal Territory of Labuan, and RM900 per month for Peninsular Malaysia (Elangkovan, 2012). The MWO applies to employers of six or more persons and began on $1^{\text {st }}$ January 2013. According to Elangkovan (2012), wages in Malaysia are largely determined by labour market forces. Malaysia’s labour market is characterised by presence of a many low-skilled workers and an over-reliance on low cost unskilled foreign workers. Such unskilled foreign workers have sustained the profitability of low value added business activity, giving businesses no incentives to increase the value-added component of their products, and have a dampening effect on wages growth. Low wage growth compared to productivity increases in Malaysia suggests an inefficient labour market and suppression of wages especially for low-paid workers. In addition to the influx of cheap unskilled foreign workers, price controls and subsidies have also contributed to low and stagnant real wages.

It therefore appears timely from a macroeconomic perspective for Malaysia to implement MWO legislation covering employees from all economic sectors because it will increase Gross National Product (Elangkovan, 2012). Gindling and Terrell (2010) consider that globalization is forcing countries to implement such legislation in order to be competitive. Introduction and enforcement of the MWO encourages employers to increase efficiency by investing in capital and other complementary factors that increase a worker's productivity. Thus by introducing a MWO, the Malaysian government is seeking to create an environment that enables job creation and poverty reduction through increasing the income of the nation's low-wage workers while at the same time enhancing firm competitiveness (Elangkovan, 2012; Todorovic and Ma, 2008).

There are a number of prior studies of the impact of a MWO (Lemos, 2009; Ni et al., 2011). Most however focus on the MWO's impact on employment while very few touch on MWO implementation challenges (Croes 
and Tesone, 2007; Ni et al., 2011). Furthermore, these studies are concentrated in developed countries (Kawaguchi and Yamada, 2007). Developing countries differ from developed countries in being less industrialized, have lower per capita income levels, high unemployment and poverty, lower life expectancy and less demand for luxuries. In developing countries have different labour institutions and law enforcement and in them a MWO affects many more people (Lemos, 2009). Therefore, studies focusing on developing countries may identify different findings. A few multi-industry studies have explored the impact of a MWO in poor and developing countries but do not examine the challenges faced by employers in the hospitality industry. A literature search did not reveal any studies of challenges faced by the hospitality industry in implementing a MWO in developing countries such as Malaysia. Therefore, this study aims to answer the question "What are the challenges faced by hotel human resource managers due to implementation of a MWO”.

The MWO implies changes in employees' pay and an increase in labour costs. The impacts of a minimum wage in developing countries are greater compared to developed countries (Todorovic and Ma, 2008). Hotels in developing countries have higher total staff numbers because the employers recruit individual employees to perform specific tasks, rather than multi-skilling, especially in five-star hotels (Nankervis, 2000). The implementation of a MWO provides an opportunity to explore the human resource (HR) management challenges faced by hotel managers in developing countries. The implementation of MWO poses a major problem to the hotel industry in Malaysia as 70\% (approximately 121,800) of hotel employees earn less than RM900 excluding service charges (MAH, 2012). Despite the crucial importance of such changes to wages, empirical studies focusing on such issues are scarce. This study is significant because in developing countries the hotel sector is labour intensive, and wage costs contribute a relatively high proportion of total operating costs (Buultjens and Howard, 2001; Guilding, 2010). Langkawi was selected as the context of this study because of the high number of hotels located in the area.

\section{Literature Review}

\subsection{Definition of Minimum Wage}

The minimum wage refers to lowest hourly, daily or monthly wage that employers are legally allowed to pay their workers (Elangkovan, 2012). Its primary function is to guarantee the minimum wage earned satisfies basic physiological and social needs of an employed individual (Kamanduliene and Paulauskaite, 2013). Most studies on minimum wages are concentrated in developed countries and the few studies that have explored the impact of MWO in poor and developing countries have examined Honduras (Gindling and Terrell, 2010), Brazil (Lemos, 2009), Indonesia (Magruder, 2013) and Pakistan (Ahmed et al., 2014). One study by Saget (2008) covered a number of developing countries. These studies are mainly concerned on economic and socioeconomic impacts of MWO implementation especially the impact on employment. 


\subsection{MWO Impacts}

The outcomes from implementation of a MWO depend on the dynamics, structure and the prospect of the labour market (Khamis, 2011). The impacts of MWO implementation in developing countries have been found to be greater compared to developed countries (Todorovic and Ma, 2008). In developing countries there is a significant informal sector where the MWO is not enforced. Findings from poor and developing countries have shown that implementation of a MWO that will benefit both formal and informal firms and the wider society is difficult to achieve within a short period of time (Ahmed et al., 2014; Elangkovan, 2012; Gindling and Terrell, 2010).

Studies in poor and developing countries indicate that a MWO is more beneficial for workers in the formal sector (Gindling and Terrell, 2010; Magruder, 2013; Saget, 2008). A MWO has led to reductions in poverty especially for workers in large firms in Honduras (Gindling and Terrell, 2010), increased the income of workers in Brazil (Lemos, 2009) and increased employment and the demand for local products in Indonesia (Magruder, 2013). However a MWO only affects those in the formal sector but not those in the informal sector (Ahmed et al., 2014; Gindling and Terrell, 2010; Magruder, 2013). The poverty reduction impact is highest among lower paid employees working in the formal economy in rural areas, and the impact is more positive when the living standard is relatively low (Gindling and Terrell, 2010).

Ahmed et al. (2014) examined wage flexibility and discovered that changes in minimum wage in Pakistan does not influence wage flexibility because the wage changes in firms is more frequent compared to the changes of the minimum wage. The author suggests that the informal sector adds to the flexibility to the formal sector due to the availability of a pool of labour. According to Saget (2008), in developing countries the minimum wage is set either too high or too low and this leads to policy failure. A minimum wage that is set too low will fail to meet social goals such as reducing poverty while one that is set too high leads to increased unemployment and non-compliance with the MWO.

The higher wages earned by employees through a MWO have a net positive impact on the economy as any minor loss of jobs is compensated for by the multiplier effect of more money in the hand of workers who are likely to spend it (Elangkovan, 2012; Magruder, 2013). Other positive economic impacts on individuals noted in prior studies are: increased efficiency of low income workers, increased labour supply, increased purchasing power of workers, greater tax revenue, reduction in the salary differentials between workers, reduction in state welfare payments, growth in the national economy, increased productivity and efficiency, and increased competitive advantages in international trade (Kamanduliene and Paulauskaite, 2013). 
On the other hand, some authors have found that MWO implementation produces negative socioeconomic impacts such as a negative effect on the employment level. This is because when an effective MWO is introduced in a free labour market, workers receive higher wages which then leads to an excess of available labour and to unemployment (Ni et al., 2011). An MWO may therefore have negative impacts by creating conditions for a cycle of poverty, leading to social problems, and reduced opportunities for training and personal development (Kamanduliene and Paulauskaite, 2013). Few studies have mentioned these MWO implementation challenges and most of these studies are concentrated in developed countries.

\subsection{The Challenge of MWO Implementation}

Certainly, the implementation of an MWO implies an increase in labour costs to employers (Croes and Tesone, 2007). This is of concern to hotel managers because the industry is labour intensive and wages contribute a relatively high proportion of total costs (Buultjens and Howard, 2001). Furthermore, low-paid employment is widespread in the hotel industry where the majority of hotel employees are clustered around the minimum wage level due to the numerous low-skilled jobs (Croes and Tesone, 2007;Warhurst, Lloyd, and Dutton, 2008). Firms may respond to increasing wage costs by reducing employment (Brown and Crossman, 2000; Croes and Tesone, 2007; Todorovic and Ma, 2008). Alternatively it may cause a transition from a labour intensive industry to a capital or knowledge intensive industry which also implies reduced employment (Ni et al., 2011).

\section{Methodology}

This is an exploratory study with the intention to assess the challenges faced by hotel managers due to the implementation of MWO. To fit this purpose, a qualitative research methodology and semi-structured interview method was adopted. A semi-structured interview method involves in-depth examination of topics with respondents providing the researcher with an opportunity to probe further depending on the flow of the discussion and hence generate rich data.

The qualitative research methodology does not use sampling logic as used in quantitative research methodology (Myers, 2009). A qualitative study is inclined towards purposive sampling and convenience sampling (Flick, 2007). At the initial stage, a purposive sampling technique is employed to decide on who should be involved in the study (Jennings, 2010). The participants for each hotel were recruited by phone. The HR Manager from each hotel served as the gatekeeper who decided whether the hotel would participate in the interview. To ensure in-depth and accurate information, only hotel managers who have been working in the particular hotel for more than one year were interviewed. Once the first few hotels have been identified, snowball sampling technique then ensues. Snowball sampling takes place when a few participants that are identified through purposive sampling are asked to give referrals to other possible respondents (Bloomberg and Volpe, 2008). The number of respondents is not pre-determined as adequacy is attained when saturation occurs, when further interviews 
yield little new knowledge (Kvale, 1996). This study focused on Langkawi hotels. The ratio of the number of various types of hotels and the number of respondents interviewed is as following: Budget hotels (11:5), Boutique hotel (2:2), One-star (3:0), Two-star (5:2), Three-star (8:1), Four-star (6:3) and Five-star (10:7). All these hotels have implemented the MWO because non-compliance will result in legal action taken against them. Altogether there are twenty respondents from nineteen hotels. Only one Five-star hotel (H19) is represented by two respondents. On average each interview took approximately 40 minutes.

The interviews were recorded, transcribed and analysed using thematic content analysis, a qualitative data analysis technique. "Content analysis is a research technique for making replicable and valid inferences from data to their context” (Krippendorff, 1980, p. 21). Qualitative content analysis involves the locating of empirical materials, developing the materials and grouping them into categories, evaluating the significance, applicability and strength of the categories and reporting the outcomes (Jennings, 2010). The inductive structure of qualitative content analysis entails the process of condensing raw data into themes or categories. These themes are based on valid inference and interpretation, and they emerge as data are being constantly examined and compared (Zhang and Wildemuth, 2009). The steps guiding the analysis of this study are consistent with that of Zhang and Wildemuth (2009) and Creswell (2007). The first step is the organising of data by systematically and thoroughly reading through each transcript to identify the challenges. Then, the condensing of data into a small number of themes by coding various challenges identified from the text into themes, and grouping the themes based on their similarities. Finally, the data is reported and presented in the form of tables or in the form of a discussion.

\section{Findings}

\subsection{Respondent's Profile}

Two owners, seventeen hotel managers, and one senior receptionist from nineteen hotels in Langkawi participated in the interviews. The managers were from various departments: eleven managers were representatives from the HR Department, while others were in-charge of the HR Department as well as other areas. The respondent's hotel experience ranged from one to thirty years. To ensure confidentiality, respondent's names were coded. For example: R1H1 refers to Respondent One from Hotel One and R2H19 refers to Respondent Two from Hotel Nineteen. The details of the respondents are given in Table 1.

TABLE 1: Respondents’ profile 
$\mathrm{R} 1 \mathrm{H} 1$

$\mathrm{R} 1 \mathrm{H} 2$

$\mathrm{R} 1 \mathrm{H} 3$

$\mathrm{R} 1 \mathrm{H} 4$

$\mathrm{R} 1 \mathrm{H} 5$

$\mathrm{R} 1 \mathrm{H} 6$

$\mathrm{R} 1 \mathrm{H} 7$

$\mathrm{R} 1 \mathrm{H} 8$

$\mathrm{R} 1 \mathrm{H} 9$

$\mathrm{R} 1 \mathrm{H} 10$

$\mathrm{R} 1 \mathrm{H} 11$

$\mathrm{R} 1 \mathrm{H} 12$

$\mathrm{R} 1 \mathrm{H} 13$

$\mathrm{R} 1 \mathrm{H} 14$

$\mathrm{R} 1 \mathrm{H} 15$

$\mathrm{R} 1 \mathrm{H} 16$

$\mathrm{R} 1 \mathrm{H} 17$

$\mathrm{R} 1 \mathrm{H} 18$

$\mathrm{R} 1 \mathrm{H} 19$

$\mathrm{R} 2 \mathrm{H} 19$
HR Manager

Hotel Executive

HR Executive

Operation Manager

Operation Manager

Senior HR Manager

Operation Manager

Operation Manager

Marketing Executive

HR Director

Director of Finance

HR Executive

Owner

Owner

HR Manager

$\mathrm{HR}$ and Account Manager

HR Director

HR Director

HR Director

Assistant HR Manager
18

7

2

30

17

18

25

1

3

18

15

3

2

2

8

12

30

18

30

20
4

Budget

Budget

Budget

2

5

Boutique

Budget

Budget

5

5

3

2

Boutique

4

4

5

5

5

5
$1: 1$

1:0.2

1:0.7

1:0.3

$1: 0.3$

$1: 1.5$

$1: 2$

1:0.2

1:0.4

$1: 4$

$1: 2$

$1: 1.3$

$1: 0.7$

$1: 1.5$

1:0.9

1:0.2

$1: 1.2$

$1: 6$

$1: 4$

$1: 4$

\subsection{The Challenge Faced by Hotel Managers due to Minimum Wage Order Implementation}

\subsubsection{Workforce Low Productivity Level}

Respondents commonly complained that some of the employees do not deserve RM900 because they are not committed to their job and are unproductive.

A lot of them are not worth the RM900. They don't turn up for work, they are not committed, they are not productive, they just don’t bother.... Their thinking is ...”When I need money I'll come to work, if not my mother dies twice, my father has three wives” (R1H14).

It is difficult to take disciplinary action towards employees who have worked in the same organization for many years. Many employees, even some senior staff, have a laid-back attitude towards work. R1H6 stated “This hotel has been operating for 20 years. For those who have work here for 20 years, to push for productivity is a little bit difficult. It is a challenge.” This is supported by R1H5 who stated "If we say something they will sulk and don't come to work the next day... Tough... Those who have worked for 15 years, 20 years, nobody touches them.” Internal disciplinary action usually will lead the manager facing an industrial court.

I do take disciplinary action, I have to, if not it is not fair to other staff... Oh Yes, I have terminated employees. I even went to the labour office a few times. I went to the labour office, and told them "this is the situation, you advise me, I follow”... DI (Domestic Inquiry, an internal hearing held by an employer to ascertain whether an employee is guilty of misconduct), everything I follow. I have never been to court because I follow procedures. The labour law is 
pro employee. They (employees) want to be smart and they want to try and push their luck, they will go. So I... if you want to go, I can go also. You present your case, I present my case, let them decide. (R1H14)

According to R1H2, R1H5 and R1H14 low productivity is common throughout Langkawi. R1H14 stated "We find that it is not the issue in just hotels... any business... grocery stores, hardware shops, anything... the biggest problem is the staff”. R1H5 compared the attitude of the staff in Langkawi with those in Kuala Lumpur (KL).

Here the mentality is different. I worked in Kuala Lumpur (KL) for about 12 years, in Middle East about three years. This is the worst experience I've had in my life. In KL, they [employees] go to KL, they work for money. Here if they don’t work, they don't mind. They stay at home. They have their parents to rely on. In KL, they go to KL to really work. (R1H5).

According to R1H2, one reason for low productivity is that the Langkawi culture encourages frequent feasts and this leads to employees absent from work.

Here they have their relatives and there is always a feast. Always... not once or twice. We always warn them in advance of the dates they are not allowed to take leave. We have the same problem with confirmed staff (full-time employees who are not under probation). (R1H2)

The issue of low productivity is also prevalent among the youngsters. R1H14 considered that this is due to the younger generation being pampered.

I think it is generation. Those who are 18, 20 years old, from what I've seen, based on our experience here, it is the generational thing... They think they deserve more without having to do anything... Maybe they have it too easy... they are not willing to take the extra mile and learn... a lot of them, their parents buy them a car, motorcycle. They live with their parents. If their parents don't have the money, they (the parents) will sell their land... There are some [Graduates] who came for an interview but don't know anything. (R1H14)

R1H14 has chosen to employ foreign workers to improve productivity even though they cost the organization more compared to the locals. She stated: “Foreign workers, we pay through an agent such as cleaning companies. We have to pay them higher than the minimum wage rate... A lot of hotels, even outside... we have to take foreign workers. It is not just Langkawi”.

Despite the difficulties of MWO implementation, the participants believe that its implementation will benefit employees and enable the country to develop. R1H5 stated: “The MWO is necessary in order [for Malaysia] 
to be a developed country. However if the rate is higher it might cause the owner to close business and many will be jobless."

While many of the responding managers/owners expressed their frustration with the MWO implementation, a few (R1H3, R1H4, R1H8, R1H9) mentioned “no problem”, as they will revise employees' remuneration system. Managers / owners who mentioned this are budget hotel operators who practice organisational flexibility. In addition, R1H8 states that MWO implementation "could be challenging for hotels with many employees” but not to budget hotels. R1H7, a boutique hotel manager mentioned that the hotel does not face any problem with MWO implementation because all employees in H7 were paid more than RM900 long before the order was issued.

\subsubsection{Many Employees with Salary below the MWO Rate}

Respondents (R1H1, R1H2, R1H5, R1H6, R1H10, R1H11, R1H12, R1H13, R1H14, R1H15, R1H16, R1H17, R1H18, R1H19 and R2H19) mentioned that the MWO implementation has increased their labour costs especially for entry level positions. In Malaysian hotels, the basic salary for new employees in entry level positions can be as low as RM400. During the off-peak season, when hotel revenue is low, the total salary (including the distribution of the service charge) does not reach the MWO rate. The Senior HR Manager from a hotel with 636 full time employees discussed this issue with a sense of frustration evident.

If the basic is RM500 and we have to top up to RM900... for one staff that's RM400, I've got over 600 staff here. How can the hotel survive? Even though we convert part of the service charge, not everybody is meeting RM900 especially the newly joined staff. We have to top up. Then, there is an increase in the Employee Provident Fundand overtime pay (R1H6).

\subsubsection{Difficulty Paying Employees due to Low Revenue}

The implementation of MWO is an even greater challenge for a five star hotel that is under construction. Hotels under construction are not able to sell all their rooms but may still have to employ most of their final staff contingent. In such hotels, employee to room ratio is very high, and the revenue generated from the room sales is not usually enough to cover the labour cost. H18 (under construction) has 6 employees for one room, the highest manning ratio of all responding hotels. Some hotels are having problems paying employees during Ramadhan, the Muslim month of fasting when fewer Malaysians travel and hence occupancy is low. R1H2 stated: "We have difficulties paying staff during the month of Ramadhan because of low revenue earned. Here, there are no customers during the fasting month.” However, at H8 MWO implementation is not an issue as 75 percent of its staff are casual workers who are called to work only when needed.

\subsubsection{The Issue of Service Charge}


Respondents in this study argued that the basic wage of non-managerial hotel employees in Malaysia is low because of the compensation provided by "service charge". According to respondents, in some months it is possible for non-managerial employees to receive more than their managers. Because of this, R1H6 expressed her dissatisfaction related to how the MWO relates to the service charge:

It is not fair for the hotel industry and it is really a burden for the hotel industry just to increase their basic to RM900 and they are still enjoying their service charge as part of it. Then their salary will be even up to RM4000 a month. That is even higher than the salary of the Restaurant Manager. Now who wants to be the Restaurant Manager? (R1H6)

This has made the implementation of MWO in the hotel industry more complicated compared to other industries. According to R1H10, R1H17and R1H18, to address this situation National Wage Consultative Council has issued guidelines that refer to a "Top-up System”. This allows payments from the service charge be included in an employee's basic salary and hence contribute to meeting the minimum wage requirements. However, this has led to another problem as R1H18 noted:

The implementation has caused some problems to this industry because many of us have collective agreements (CA)...When the Government gives an order, we must follow. But the issue comes into place when the Government comes up with a guideline for the hotel industry. The guideline said "As for the hotel... you can add in your service charge to be part of minimum wages.” This is known as the Top-up System. The Union does not accept that. When it goes to court, [as in the] Crystal Crown case, the hotel loses! (R1H18)

The case referred to by the respondent is National Union of Hotel, Bar and Restaurant Workers, Peninsular Malaysia v. Crystal Crown Hotel and Resort Sdn Bhd (2014). R1H17 provided an explanation of the case. According to R1H17, in this case, the court argued in its decision that the service charge does not come from or belong to the hotel. Instead, it is paid to employees under their contract of service with the hotel as a reward for their service. Therefore the court ruled that the service charge collected by the Crystal Crown Hotel and Resort should not be considered remuneration under employees' contract of service with the hotel, or treated as a part of employees’ wage.

The respondents interviewed were concerned about this case and its implications. The general belief is that the rate of minimum wages will be increased and the allowance to use Top-up System money in basic wage calculations will be discontinued. For R1H10, the "blurred and grey" guidelines are making MWO implementation by management and owners difficult. This respondent noted: 
The government suggested the Top-up System but it is blurred and grey. In future, the MWO will be revised and increased and hotels may not use Top-up System any more. Hotels do not know which way to go, making it inconvenient for owner and management. It is difficult especially when the owner is not Malaysian. (R1H10)

According to R1H19, it would be easier if the guideline adopted "take home pay" as the way the basic wage is calculated, where "take home pay" is defined as basic salary plus other forms of monetary payment. In order to avoid having legal problems, H18 has not signed any CA with the union related to MWO despite the pressure from the union.

In my hotel, we have not been able to find agreement up to now. It has been a pending issue since the MWO came out... I said [to the union] "how can I put my signature, it’s like putting my head in a noose”... Once you sign the CA, the employees will get some back-dated payment, adjustment, just like that. A few hotels in Langkawi have signed the CA. They have signed it and they're going to court (R1H18).

Other hotels either changed their remuneration or increase employees' basic salary to at least RM900 without touching their service point system. Six of the hotels interviewed (H1, H5, H7, H8, H12 and H18) adopted a “Clean Wage System” that does not include service charge points as a part of employee's remuneration. According to R1H1, the Clean Wage System has resulted in employees' dissatisfaction and increases in turnover. R1H15 stated that H15 increased its employees' basic salary to at least RM900, and this resulted in labour cost increases.

\section{Discussion}

\subsection{Problems with Langkawians Attitudes, Work Ethic and Work Culture}

The issue of an unproductive work force, especially senior employees and the younger generation was mentioned by a number of respondents. A majority of the workforce are Langkawi residents who are said to have a laid-back attitude towards work. Most Langkawians are Malay and their attitudes, work ethics and work culture as reported in this study are consistent with those reported by Mohamad (2011). One Malaysian former Prime Minister, Tun Mahathir Mohamad, has highlighted problems with the Malays’ attitudes, work ethics and work culture stating:

The trouble is the majority of the Malays have not yet learnt the uses of money. For them it remains merely a convenience, a means of exchange for buying or acquiring goods and services, and gaining status. Money is still not regarded as capital that can be managed and invested in order to earn more money. (Mohamad, 2011, p.233) 
When asked if Malays in general are lazy, one resort owner interviewed mentioned that it is not only the Malays who have bad attitudes and work ethics and in fact, there are Malays who perform better than the non-Malays and this is supported by a resort manager who mentioned that the Malays in Kuala Lumpur are different. Mohamad (2011) also mentions that some Malays have engaged with the modern world and developed a work ethic. The younger generation in Langkawi is also considered to have a poor work ethic due to being pampered by their parents, who are willing to sell their land so their children can buy a car.

On one hand these finding suggests that local workers, especially the senior employees and the younger generation have a relaxed attitude towards work because they are in their comfort zone. On the other hand it suggests that the local workers are not keen to be in the hospitality industry, a low wage industry with mundane jobs and limited career advancement opportunity. The hotel industry is one where people with better opportunities do not seek employment and immigrants are the preferred employees (Ahmad et al., 2014 ; Talwar, 2001). Similarly, restaurant managers in Brooklyn, New York have a negative impression towards the American-born workers in comparison to the positive traits of the immigrants, mentioning that American-born workers “don’t want to work”, “want something for nothing” and “are not looking ahead” (Talwar, 2001, p.97).

\subsection{Labour Cost Increased}

Four and five-star hotels that have many employees with a salary below the MWO are affected significantly by increased labour costs. Budget hotels in Langkawi that practise organisational flexibility (functional flexibility and numerical flexibility) are less affected, suggesting implementation of the MWO is a bigger challenge for hotels promising higher service levels. The utilisation of labour in four and five-star hotels is higher than budget hotels because employers practice job specialisation in which they recruit individual employees to perform each and every task to fulfil the service promised (Haron, 2012). In developed countries job specialisation is only used for complex tasks (Fraser and Hvolby, 2010).

Due to increased labour costs, some budget hotels that are highly dependent on the local Muslim market and which have many full-time employees experience difficulties in paying employees during Ramadhan. While it is common for many hotels in Langkawi to experience less revenue in the month of Ramadhan, not all hotels have problems paying their employees. Some budget hotels do not face problems paying employees because of the high number of casual workers who are called to work only when needed. While authors from the developed countries have argued against casual employment (Davidson et al., 2006), the results of this study indicate that it is necessary for hotels to practise some degree of casual employment in order to survive and remain competitive. However, the practise of casual employment implies decreased full-time employment due to the reduction of the number of employees as was found by Ni et al. (2011). 


\subsection{The issue of Service Charge and the Guideline that is not Consistent with Other Existing Acts}

The implementation of MWO has led employers to adjust employees' remuneration. Employers either directly follow the order by increasing employees’ basic salary to RM900, or adopt a Clean Wage System or Top-up System. Of these three methods, the first is the most costly to employers, the second dissatisfies employees the most, while the third is not that costly to the employer and does not decrease employees' take home pay. However, Top-up System does not comply with existing laws.

The hotel industry has a salary structure that is different from other industries in Malaysia. In particular, it will often include a service charge included in the visitors hotel charges that is distributed to staff as part of service improvement systems.

A fixed service charge (normally 10\%) is levied on the customers' bills, which must be paid. The money is paid into a fund called the service charge fund. What started off as a trade practice has now been incorporated into collective agreements whereby $10 \%$ of the fund is taken by the hotel to defray the administrative costs incurred for the maintenance of the fund and the remaining $90 \%$ is distributed to the eligible employees in accordance with the service point allocation under the collective agreement.Hence the hotels today are contractually bound to make monetary payments to the employees based on their service charge points (National Union of Hotel, Bar and Restaurant Workers, Peninsular Malaysia v. Crystal Crown Hotel and Resort SdnBhd, [2014] 3 MELR134at149).

The Guidelines on the Implementation of the MWO 2012 clearly provide that "for the hotel sector where the service charge collection is implemented, the employer may convert all or part of the service charge meant for distribution to the employee, to form part of the minimum wages” (National Wages Consultative Council, 2012, p.5). However, the guideline is arguably in dispute with The National Wages Consultative Council Act 2011 (Act 732) and Employee’s Provident Fund [Amendment] Act 1986 which do not allow hotels to include service charge as part of a basic salary (National Union of Hotel, Bar and Restaurant Workers, Peninsular Malaysia v. Crystal Crown Hotel and Resort Sdn Bhd, 2014). As a result, employers face implementing conflicting guidelines.

\section{Implications}

\subsection{Adoption of Human Resource Practices System}

To increase productivity, the adoption of a human resource practices system is a necessity (Hoque, 2000). Selective staffing ensures the employment of employees with the right attitude. Organisational flexibility 
enables business to operate smoothly with fewer employees. To run and organisation smoothly with fewer employees, the employees must be trained to practise functional flexibility and empowered to make decision (Desombre et al., 2006). In return to their increased workload, skill and productivity, they need to be rewarded with fair and competitive remuneration. A hotel which compensates employees based on performance instead of seniority can retain committed employees, and avoid them becoming too comfortable. It is also crucial to take disciplinary action against problematic employees as portrayed in the findings of this study. This is consistent with Human Resource Practices System which highlights the synchronisation of all human resource practices (Hoque, 2000).

\subsection{Adoption of Organisational Flexibility}

To overcome the increased labour cost, hotels need to practise functional and numerical organisational flexibility (Desombre, Kelliher, Macfarlane and Ozbilgin, 2006). Functional flexibility allows employees to be reassigned to different jobs or tasks, while numerical flexibility refers to the employment of part-time and casual workers during periods of full occupancy (Peel and Boxall, 2005). Responses such as reducing the number of employees, training staff to be multi-skilled, increased use of better quality staff, and using more part-time and casual workers appear relevant (Brown and Crossman, 2000; Radiven and Lucas, 1997). Radiven and Lucas (1997) have suggested changes in employment contracts, remuneration, grading structure and training can address issues for hotels in implementing an MWO.

\subsection{Action that Abides to the Governing Rules and Regulations}

Policy makers and organizations must always ensure that their actions are consistent with and abide by a country's governing rules and regulations. Implementation of inconsistent policy may cause economic loss, as well as frustration and judicial lawsuits from unions or other bodies; problem which can be costly to a hotel. This study has discussed examples of employers' cautiousness in signing agreement with a union, and in taking disciplinary action towards employees. Before signing an agreement with the union the HR Director in a five star hotel must analyse the cost and consequences of signing an agreement. She must also be aware of the outcome for hotels that have signed wage agreements, and of the reasons for problematic outcomes. The owner of a boutique hotel may need to seek advice from the labour office due to a lack of expertise in laws related to HR. She may also hire a HR consultant to ensure that the policy and practices in her company abide by the government's laws, rules and regulations. This is consistent with strategic HR management which postulates that it is crucial for the HR managers to be alert, aware and to react to such rules and regulations, and to the current issues in the hotel industry (Devanna et al., 1981).

\subsection{Active Involvement of all Stakeholders in the Guideline Development}


Guidelines on the Implementation of the MWO 2012 were developed by the National Wages Consultative Council. Prior to these guidelines, the Council held meetings with stakeholders including hotel operators. However, few hotel operators participated in these discussions. Ferrary (2009) considers that any organisation is a part of a politico-economic system of stakeholders who interact and influence management practices, and each stakeholder tries to optimise and protect his interests. When all stakeholders are actively involved in these discussions, conflicts between employees and their employers can be avoided or reduced. However, this requires understanding the nature and strategy of stakeholders, alliances and means of action, and complying with the obligations of the labour and other existing laws. The stakeholders' interactions may be indirect through Associations and representatives. Thus the effectiveness of the interaction may depend on strategies adopted by the Council to involve all the stakeholders, and when the interactions are not strictly determined, it opens perspectives for stakeholders to take it lightly until it is too late.

\subsection{Local Community Awareness}

This suggests that local's attitudes, work ethic and work culture may need to change in order to remain preferred employees and avoid increased use of foreign workers. The government's objective in MWO implementation is to increase Malaysia’s Gross National Product and economic growth. An influx of foreign workers will decrease the economic benefit to Malaysia as these workers usually save the money earned to be transferred and spent in the country of their origin. Changes in the local community's attitudes, work ethics and work culture may avoid locals being a "deprived, dispossessed and marginalised” community in their own country (Mohamad, 2011).

\section{Conclusion}

This study suggests that the challenges faced by hotel managers in Langkawi due to the MWO implementation include workforce low productivity levels, many employees with a salary below the MWO rate, difficulty paying employees due to low revenue and the issue of the service charge. Despite these challenges, a majority of the hotel managers support an MWO. To handle these challenges, HR managers need to adopt Human Resource Practices System and organisational flexibility, and abide to the governing rules and regulations. However for the MWO to be effective, it is crucial for the government to develop effective guidelines, and for local employees to increase their productivity level. The findings of this study contribute to the industry, policy makers and community by highlighting how to improve the implementation of the MWO. This study may also benefit other developing countries that are considering a MWO policy.

This study is an initial qualitative exploratory study based on interviews with 18 hotel managers and two hotel owners in Langkawi. Thus, the findings cannot be generalised. For a more detailed information and effective solution to the challenges, future studies could focus on policy makers, employers or the community. It is 
worthwhile to explore the community’s perspective on work ethics and culture. Quantitative study can also be conducted to allow for generalisation.

\subsection{Acknowledgements}

This study is funded by Research Acculturation Grant Scheme (RAGS).

\section{References}

Ahmad, R., Rashid, B. and Mohd-Shariff, N. (2014), “Malaysian hospitality industry: Graduates’ justifications for leaving the industry”, International Journal of Management Studies, Vol. 21 No. 2, pp. 1-20.

Ahmed, W., Choudary, M.A., Khan, S., Naeem, S. and Zoega, G. (2014), “Determinants of wage stickiness in a developing economy”, Economic Modelling, Vol. 38, pp. 296-304.

Bloomberg, L. D., and Volpe, M. (2008),Completing your qualitative dissertation, Sage, Thousand Oaks.

Brown, D. and Crossman, A. (2000),“Employer strategies in the face of a national minimum wage: An analysis of the hotel sector”, Industrial Relations Journal, Vol. 31, No. 3, pp. 206-219.

Buultjens, J. and Howard, D. (2001),“Labour flexibility in the hospitality industry: Questioning the relevance of deregulation”, International Journal of Contemporary Hospitality Management, Vol. 13 No.2, pp. 6070.

Creswell, J. W. (2007), Qualitative inquiry \& research design: Choosing among five approaches, 2nd ed., Sage, Thousand Oaks.

Croes, R. and Tesone, D. V. (2007), “The indexed minimum wage and hotel compensation strategies”, Journal of Human Resources in Hospitality and Tourism, Vol. 6 No. 1, pp. 109-124.

Davidson, M., Guilding, C., and Timo, N. (2006). "Employment, flexibility and labour market practices of domestic and MNC chain luxury hotels in Australia: Where has accountability gone?”, International Journal of Hospitality Management, Vol.25 No. 2, pp. 193-210.

Desombre, T., Kelliher, C., Macfarlane, F. and Ozbilgin, M. (2006), "Re-organizing work roles in health care: Evidence from the implementation of functional flexibility”, British Journal of Management, Vol. 17 No.2, pp. 139-151.

Devanna, M. A., Fombrun, C. And Tichy, N. (1981), "Human resource management: A strategic perspective”, Organisational Dynamics, Vol. 9 No.3, pp. 51-67.

Elangkovan, K. (2012), "Minimum wage laws in Malaysia: An answer to the increasing rate of unemployment”, International Journal of Academic Research in Economics and Management Sciences, Vol. 1 No.5, pp. 135-146.

Ferrary, M. (2009), “A stakeholder’s perspective on human resource management”, Journal of Business Ethics, Vol. 87, pp.31-43.

Flick, U. (2007), Designing qualitative research, Sage, London. 
Fraser, K. and Hvolby, H.-H. (2010), "Effective teamworking: Can functional flexibility act as an enhancing factor? An Australian case study”, Team Performance Management, Vol.16 No.1/2, pp.74-94.

Gindling, T.H. and Terrell, K. (2010), “Minimum wages, globalization and poverty in Honduras”, World Development, Vol. 38 No. 6, pp. 908-918.

Guilding, Chris. (2010), “Basic elements of cost”, in A. Pizam (Ed.), International encyclopedia of hospitality management, Heinemann, Oxford.

Haron, A. S. (2012), We must think lean and mean. New Straits Time. http://www.nst.com.my/opinion/columnist/we-must-think-lean-and-mean-1.27123

Hoque, K. (2000), Human resource management in the hotel industry: Strategy, innovation and performance, Routledge, London.

Jennings, G. (2010),Tourism Research, 2nd ed., John Wiley \& Sons, Australia.

Kamanduliene, A. and Paulauskaite, G. (2013), “Assessment of economic and social impact of minimum wage on individuals”, TaikomojiEkonomikaSisteminiaiyrimai, Vol. 7 No. 1, pp. 117-135.

Kawaguchi, D. and Yamada, K. (2007), “The impact of the minimum wage on female employment in Japan”, Contemporary Economic Policy, Vol. 25 No. 1, pp. 107 - 118.

Khamis, M. (2011), “Does the minimum wage have a higher impact on the informal than on the formal labour market? Evidence from quasi-experiments”, Applied Economics, Vol. 45 No.4, pp. 477-495.

Krippendorff, K. (2004), Content analysis: an introduction to its methodology, $2^{\text {nd }}$ ed., Sage, Thousand Oaks. Kvale, S. (1996), Interviews: An introduction to qualitative research interviewing, Sage, Thousand Oaks.

Lemos, S. (2009), “Minimum wage effects in a developing country”, Labour Economics, Vol. 16 No. 2, pp. 224-237.

Magruder, J.R. (2013), “Can minimum wages cause a big push? Evidence from Indonesia”, Journal of Development Economics, Vol. 100, pp. 48-62.

Malaysian Association of Hotels. (2012), Joint Malaysian Association of Hotel Owners, Malaysian Association of Hotels, Association of Hotel Employers and Malaysian Budget Hotels Association memo to National Wages Consultative Council [pdf], Retrieved from https://uummail.uum.edu.my

Mohamad, M. (2011), A doctor in the house: The memoirs of Tun Dr Mahathir Mohamad, MPH, Petaling Jaya. Myers, M.D. (2009), Qualitative research in business and management, SAGE, Thousand Oaks.

Nankervis, A. (2000), "Human resource management strategies as competitive advantage: A case example of the hospitality sector in Southeast Asia and the Pacific rim”, Research and Practice in Human Resource Management, Vol. 8 No. 1, pp. 111-133.

National Union of Hotel, Bar and Restaurant Workers, Peninsular Malaysia v. Crystal Crown Hotel and Resort Sdn Bhd [2014] 3 MELR134 
National Wages Consultative Council. (2012), Guidelines on the Implementation of the Minimum Wages Order 2012, MoHR, Putrajaya.

Ni, J., Wang, G. and Yao, X. (2011), “Impact of minimum wages on employment: Evidence from China”, The Chinese Economy, Vol. 44 No. 1, pp. 18-38.

Peel, S. and Boxall, P. (2005), "When is contracting preferable to employment? An exploration of management and worker perspectives”, Journal of Management Studies, Vol. 42 No. 8, pp. 1675-1697.

Radiven, N. and Lucas, R. (1997), “Abolition of wages councils and the introduction of a national minimum wage with particular reference to British hotels”, International Journal of Hospitality Management, Vol. 16 No.4, pp. 345-359.

Saget, C. (2008), "Fixing minimum wage levels in developing countries: Common failures and remedies. International Labour Review”, Vol. 147 No. 1, pp. 25 - 42.

Talwar, J.P. (2001). "Contradictory assumptions in the minimum-wage workplace: A focus on immigrants, the American-born, and employer preferences in Brooklyn, New York, Journal of Contemporary Ethnography, Vol.30 No. 1, pp. 92-127.

Todorovic, Z.W. and Ma, J. (2008), “A review of minimum wage regulation effect: The resource-based view perspective”, Journal of Collective Negotiations, Vol. 32 No. 1, pp. 57-75.

Warhurst, C., Lloyd, C. and Dutton, E. (2008), “The national minimum wage, low pay and the UK hotel industry: The case of room attendants”, Sociology, Vol. 42 No. 6, pp. 1228-1236.

Zhang, Y. and Wildemuth, B. M. (2009), “Qualitative analysis of content”, Applications of Social Research Methods to Questions in Information and Library, pp. 308-319. 